\title{
Research on Cross-cultural Adaptability Demands for Expatriates
}

\author{
Yan Wang* \\ Training Department \\ Xi'an International Studies University \\ Xi'an, Shaanxi, China \\ 1036216578@qq.com
}

\author{
Bei Wu \\ School of International Languages \& Cultures \\ Yunnan University of Finance \& Economics \\ Kunming, Yunnan, China \\ 16501955@qq.com
}

\begin{abstract}
This study mainly investigates the demands of cross-cultural adaptability for expatriates in Shaanxi enterprises. It aims to understand the relationships among English ability, curriculum models, and cultural resilience of these people through questionnaires and interviews, and analyze the difficulties and demands of cross-cultural communication in overseas work and life. The study can provide a reference for corporates to determine course material, course forms, and teachers' ability in cross-cultural communication training. It will provide guidance for future development of English training for corporate expatriates in Shaanxi province.
\end{abstract}

\section{Keywords—cross-cultural adaptability; expatriates}

\section{INTRODUCTION}

In the current environment of economic integration, China is gradually demonstrating its rapid development through transnational cooperation. "The Belt and Road" initiative was proposed in 2013, and the summit forum on it was hold this year. Past four years have witnessed deepened policy communication, and closer cooperation in such fields as facilities, trade, capital finance, and culture, between China and the participating countries. Cooperation has been continuously improved and strengthened. As an important link of "The Belt and Road" initiative, Shaanxi has undergone increasing foreign economic cooperation and markedly accelerated pace of "going global". According to the report of the Shaanxi Provincial Bureau of Statistics, during the "12th Five-Year Plan" period, the province's newly increased foreign contracted projects totaled 7.009 billion U.S. dollars, with a cumulative turnover of 7.426 billion U.S. dollars, and a 2.5-fold increase over the "Eleventh Five-Year Plan".

From the view of foreign labor cooperation, the total real income of Shaanxi foreign laborers reaches 364 million US dollars with an average annual increase of $56.1 \%$; and 28777 laborers of various types are sent abroad with an average annual growth rate of $58 \%$. From the view of overseas investment, 136 newly foreign-funded enterprises (including 67 foreign institutions) has been set up in Shaanxi. The province's overseas investment spreads over Hong Kong, the United States, Thailand, Kyrgyzstan and other countries and regions, covering fields of equipment manufacturing, mineral resources exploration and development, real estate, wholesale

*Corresponding author and retail and other fields.

As Shaanxi enterprises are involved in more and more overseas fields, the demand for practitioners who boast both professional skills and foreign language skills is also expanding. At the same time, since the globalization development strategy requires a large number of employees with cross-cultural management and execution capabilities, the expatriation of personnel has become an inevitable trend in Shaanxi. In order to enable expatriates to adapt to the host country's culture better, cross-cultural training, as one of its influencing factors, should bring to the attention.

This study is a response to China's strategy of building "The Belt and Road" and the policy of opening up to the outside world. It adapts to the increasing trend of external capital output and industrial output year after year, and also an important part of the supporting services in the foreign economic and trade cooperation. It will lay the foundation for the rapid development of staff with high-level foreign language skills and strong cross-cultural adaptability, and provide enterprises with more promising expatriate talents. It is an essential factor for enterprises to send personnel to work abroad to advance internationalization. Expatriates should have the ability to establish customer markets and open more communication channels in overseas branch offices. What's more important is that they should be able to pass on corporate culture and win more opportunities for exchanges and cooperation with foreign countries. However, when expatriates come to a completely strange cultural environment, they will face many changes and conflicts, such as living habits, moral ideas, and values.

They may not only have difficulties in their work, but also feel apart from the whole environment, thus leading to many physiological and psychological diseases in serious cases. This is mainly because there is a huge cultural difference between the home country and the destination country in terms of values, social behavior, thinking patterns, and cognitive processes. There have been investigations showing that $20 \%$ to $50 \%$ of expatriates return to their country in advance because they cannot adapt to the local socio-cultural environment. Therefore, we must pay more attention to the improvement of language and cross-cultural adaptability. It is also necessary to incorporate cross-cultural adaptability content into language training so that expatriates can be fully equipped. 


\section{LITERATURE REVIEW}

The clear definition of "cross-cultural adaptation" in academia was first proposed by the American anthropologist Redfield et al. [1]., and the "cross-cultural adaptation" was defined as changes caused by personal contact between individuals from different culture. There are plenty of studies on cross-cultural adaptation at home and abroad. The foreign research on cross-cultural adaptation has been carried out from both theoretical and empirical perspectives while domestic research is conducted on the basis of learning and developing foreign studies, and most of them are theoretical.

Some scholars identifies the so-called "cross-cultural adaptability" as a balance between the individual and the new cultural environment-that is "the fit of individuals and their environment" [2].; and other scholars argue that cross-cultural adaptation can be described as the degree to which expatriates feel comfortable on different psychological levels (including habits, religion, values, etc.) or the adaptation process to life and work in different cultural settings [3].

At present, domestic and foreign scholars seem to agree on the concept of cross-cultural adaptation [4]. that is, cross-cultural adaptation is the physical and psychological reactions that occur when individuals expose to another culture, or is defined as a process where individuals' senses of belonging and self-identity are changing during their live or work in a non-native cultural environment. And this process is generally psychological, positive, and measurable.

Many foreign scholars suggest that Cross-Cultural Adaptability (CAA) is considered to be one of the core factors to ensure successful external assignments since it can predict the effectiveness and successful odds [5]. The factors that affect the cross-cultural adaptability can be divided into three categories: socio-cultural environment, organizational factors, and individual characteristics. Among these three, the socio-cultural environment is an aspect that we should focus on and pay attention to in our pre-departure foreign language training. The socio-cultural environment includes cultural differences between home country and destination country, the politics and economy of destination country, and the cultural attraction and taboos of destination country. The training effect of social and cultural factors may directly influence post-departure personnel's job adaptability, life adaptability, and interaction with the target country's people [6].

China is a late starter in the research of cross-cultural adaptation of expatriates and also lacks sufficient research. The limited researches in China are mostly based on related foreign theories and they are reviewed theoretically from the psychology or culture perspectives, while evidence-based research is extremely rare [7]. With the strengthening of communication among multinational corporations, cross-cultural training programs have received increasing attention. Many companies provide employees with cross-cultural training to help them adapt to the foreign environment. Some surveys show that there is a positive correlation between cross-cultural training and cross-cultural adaptation. At the same time, cross-cultural adaptation is also positively correlated with the performance of expatriates. However, the cross-cultural adaptation of Chinese expatriates is less than ideal and the existing cross-cultural training does not solve this problem neatly [8].

\section{RESEARCH DESIGN}

This study involves the cultivation and improvement of language ability and cross-cultural adaptability, as well as the reform and upgrade of curriculum model. At the same time, it has a lot to do with the analysis of personalized teaching and students' needs. In order to improve the pertinence and practicality of the study, we adopt the literature review and interviews as our principal tools. On the one hand, we collect research results at home and abroad in recent years. On the other hand, we learn about language skill and cross-cultural adaptation of expatriates and their needs in these two areas through direct interview`s. Through analysis and summary, the relationship between language ability, curriculum model, and cultural resilience of the expatriates in the learning process is investigated. The foreign language ability and cross-cultural adaptability of expatriates are investigated to supplement the research on cultural resilience of them. The research tries to identify the gap between foreign language and cross-cultural adaptability and the status quo of the expatriates in Shaanxi foreign-oriented enterprises so as to propose feasible suggestions for the reform of foreign language training models, and enriches English training theories for expatriates.

Interviews are conducted through face-to-face way and online tools such as QQ or WeChat to understand language and cross-cultural needs of expatriates in their daily lives and work, and to consult employers and expatriates on their suggestions on training courses. After many joint efforts, we have contacted 31 expatriates who are working overseas and conducted detailed inquiries about communication issues they are encountering in their work and life to learn whether the foreign language training has practical significance after going abroad. We also solicit their advices on the future improvement of training courses on the basis of their overseas experience. The 31 interviewees come from five different enterprises and are dispatched to nine different countries. Aging between 31 and 45 years old, they are first-tier engineers and project managers. In addition, we also conducted interviews with managers of five companies to further understand whether our pre-departure English training on expatriates is successful from the point of view of the managers, and whether the employer is satisfied with their works abroad. We also listen to management's opinions on the English training we provide.

\section{RESEARCH RESULT}

\section{A. Investigation of Cross-Cultural Cognitive Ability of}

\section{Expatriates}

Through the interviews, we find that expatriates have a good sense of cultural differences, but middle ability to experience cultural differences. In other words, they can recognize the differences between Chinese and foreign cultures, and they can also realize that the culture of host country has quite different characteristics with that of their own countries. However, they lack understanding of the specific and different contents and characteristics of destination country. These 
expatriates have the subjective initiative to experience cultural differences, but their ability to experience cultural differences remains to be improved.

Four respondents mentioned religious culture in destination countries and some problems they encountered about it. One of the staff who was sent to the United Arab Emirates said:

Basically, I adapted to the local culture and customs since they are very inclusive with east meeting west. There are $80 \%$ of immigrants, thus culture is not restricted to Arab culture. I integrated into the local community in less than 3 months. Local people do not like to take photos of them and sensitive buildings, and it is forbidden to eat or smoke in public during Ramadan. At the time, I drank water when shopping in supermarket since I forgot this custom, thus attracting many people's attention. Later I realized that this was not allowed and it is doomed to prison in the local area. What' more, many Chinese people were caught in prison due to taking pictures. Fortunately, I saw the prohibition mark before taking a picture and failed to cause great trouble.

In addition, some people said that when they visited a Frenchman or Finns, they could realize that they should come with a gift, but they did not know what gift, wine or chocolate, they were supposed to bring, and which one was more suitable in local customs. Another interviewee mentioned that culture is core, and it has some manifestations, such as sense of time, taboos, etc. But it will take a long time to perceive its deeper connotations since they cannot be realized within a short time. Respondents said that they did not get a word in when chatting with French colleagues about current affairs or some issues, and also they knew little about life in Europe.

All these indicate that the expatriates are conscious of the cultural differences, but they lack culture experience and understanding of the destination country. Just as one interviewee mentioned that they are satisfied with the cultural curriculum, but it is difficult to cover all aspects due to the huge cultural differences among countries. At the same time, there is still a distance from being able to realize differences and to experience the differences. Most interviewees had more experience with language when answering questions. Although there are cultures involved, the feeling of language is significantly more than that of culture in terms of quantity and quality. Everyone gives a relatively detailed description of the status quo and difficulties in language, but only about half of them can make specific statements about cultural adaptation. It can be seen that the experience on culture is still relatively lacking. Most people's feelings about culture mainly focused on religious, dining, festivals and social communication.

From result of the interview, most expatriates have some knowledge of key features of different cultures, but it is not profound and extensive enough. They know little about the key features of culture and pay little attention to the cultural phenomenon of host countries. Just as one of the interviewees said, "In addition to language, there are also customary problems, and for example, Thai people ride motorcycles on the left side. I can't help but ride on the right side, thus incurring blames from them." And another interview said "(I am) In the United Arab Emirates, I adapted to the local culture and customs very quickly. The local culture is very inclusive with integrations between east and west. $80 \%$ people are immigrants, thus the culture is not limited to Arab." Other words like "Fijians are bad-educated", "local economy and education are backward," "I use Alipay and WeChat in China. But after coming to Europe, they use what's up. We don't know much about it", and "In addition to work, we talk with colleagues about others things, but we don't like what they talk about politics and religious" and so on. It can be seen that they lack knowledge about the key features of culture. Their views of culture are macro and are all about daily life. Their overall understanding of key cultural features is neither extensive nor profound.

\section{B. Survey on Cross-Cultural Adaptability of Expatriates}

From the interviews, we can see that most expatriates can respect cultural differences, and more than $90 \%$ of them are able to adjust their emotions and behaviors and respect the culture of the destination country after realizing cultural differences. For example, one interviewee mentioned:

After going abroad, I often go out to dinner with my colleagues. In public places (restaurants), Chinese people always pour to order meals or inquire, and they speak loudly during dining, which makes the locals very nervous. And they always ignore their bad behaviors until others point them out after a long time. Afterwards, we pay attention to the locals' practices in public places at first, and then learn what they do.

Respondents adjust their behaviors according to the culture of the destination country, fully demonstrating that trained expatriates were able to respect the culture differences between countries. However, from the interviews, it can be seen that they respect cultural differences through concessions and avoidances. They exercise great care as if treading on thin ice, and thus it is impossible to detect reasons for cultural differences on the basis of full respect and propagate their own culture without any misunderstanding and conflict so that it can be well integrated into the local culture. We believe that this has something to do with their lack of deep-level linguistic abilities and understanding of the motherland's cultural essence.

According to interviews, most of expatriates are aware that they need to adjust themselves to cope with cultural conflicts, but many people are not confident to handle the cultural clashes of the home country culture. According to feedbacks, more than $75 \%$ of the respondents felt that the hugest clash with their home countries is the "linguistic and behavioral taboos." More than $60 \%$ of people thought that "eating and dining etiquette" is difficult to adapt to and grasp. And other interviewees said it is hard for them to accept local people's sense of working hours and working pace, thus causing inconvenience in their work.

An expatriate working in the UAE stated that many words on the menu were not known when dining out. In the training, the teacher mainly introduced foods for countries such as the United Kingdom and the United States without mentioning those of destination country, so they were less familiar with local expressions on foods, and they could only choose fast food and give up eating at local restaurants. Not only that, many respondents stated that they had given up the 
opportunity to go out dining because they did not understand the dining etiquette of the destination country (such as how much to tip after dinner). Respondents from an Africa destination country mentioned that the food culture he learned is about developed countries. It has no use to adapt to the host country's habits because it is too different from the home country. He is simply unused to dinning way (eating with hands), and do not want to adapt. In the face of cultural conflicts, most of expatriates are not confident to cope and overcome. Most of them chose to live and work in a very small area, while others would reduce the chances of communicating with others deliberately. Most of them adopt evasion attitudes with regard to cultural conflicts, let alone respond positively.

\section{CONCLUSION}

With help of research results and related cross-cultural adaptation theories, we should make use of existing resources to cultivate and improve cross-cultural adaptability of expatriates from the following aspects: curriculum adjustment, textbook compilation, improvement of targeted teaching, teacher training, and platform building.

Firstly, the training has to be well-directed. It is necessary to make a comprehensive explanation in cultural knowledge of the destination country since it varies from place to place. Although European and American culture have a great influence on the world, from which destination countries are different. As a result, the basic cross-cultural knowledge can be in common use, but the specific cross-cultural adaptability must be directed at the destination country. In addition, training should not be limited to the mass cultures in daily life, and it should focus more on deep culture content and the nature of the expatriates' work. Only in this way can we build a three-dimensional cultural training structure and establish a knowledge reserve for expatriates, and wherein knowledge includes the following three aspects:

\section{A. Training and Popularization of Surface Cultures (the Operating Modes and Characteristics of People's Daily Life in Destination Countries)}

This part presents the most basic cultural knowledge, which is crucial for expatriates to adapt to local life. They are able to integrate into the local community quickly and meet their own living needs better through learning local culture in advance. The basic knowledge mainly includes traffic conditions, public facilities, tourist information, accommodation, shopping, dining, social etiquette, currency, holiday customs, and climate and so on.

\section{B. Understanding of Deeper Culture (the Overall Cultural (Atmosphere or Ideology of the Destination Country.)}

Such contents as political system, historical civilization, religious beliefs, thinking patterns, communication ways, space-time concepts have a great influence on surface culture. Understanding deeper culture contents will help expatriates improve their cultural awareness and adapt to the entirely different cultural atmosphere in the destination country. We propose a three-step approach to study deep culture: 1) Expatriates should take the initiative to understand their own culture, through which they can empathize with other cultures rapidly and thus accept them easily. 2) They should learn about the major historical, political and economic events of the destination country. 3) They should learn the potential values and beliefs behind the cultural phenomenon of the destination country.

\section{Cultural Knowledge Related to the Expatriates' Work (Including Business Culture, Negotiation Culture, Marketing Culture, etc.)}

The expatriates are sent abroad to work, whose main task is to complete their tasks. Therefore, it is necessary to increase the work-oriented cultural course in the training. Different countries have different cultural atmospheres in different aspects of business activities. Cultures are ingrained in such business situations as dressing, etiquette, communication ways, and methods of resolving contradictions business situations, and these are also indispensable for training.

The second one is about the development of language skills and cross-cultural communication skills. The mastery of local language is of crucial importance to the cultural adaptation for expatriates. In addition to languages, non-linguistic factors are also very important in the communication process. This includes the behaviors, body language, and speaking ways and other aspects. Therefore, we must improve the ability of expatriates from both language and cross-cultural communication. It mainly includes the following skills:

\section{Language Skills, that is, English Training for Survival.}

The language training must be combined with the language characteristics of destination country. Although English is the most commonly used language in international business, differences of it among countries are significant, especially in pronunciation and expression. Therefore, in addition to improvement of English skills, characteristics of target country's English should be taken into consideration, such as pronunciation characteristics and local special expressions of Indians when they speak English or the special English in other countries. These skills should include surface cultural knowledge mentioned above so that cultural knowledge can be translated into language skills.

\section{E. Non-language Skills, i.e. Body Language, Behavior,} Communication Skills, etc.

In cross-cultural communication, non-verbal communication accounts for a large proportion. How to use body language correctly, how to keep a proper distance in communication, how to conform to the sense of time of destination country, and how to understand the silence in different situations., and all of these are related to non-verbal communication. Different countries also have different interpretations and expectations for these. Therefore, non-verbal communication training should also be brought to the forefront.

In order to foster better psychology, knowledge and skills, the training party should improve training contents, methods and courses from the following aspects.

First, improve and reform the curriculum. Specific courses should be set up to improve cross-cultural adaptability. In addition, it is necessary to develop cultural awareness in daily listening, speaking, reading and writing training. The course 
needs to include both the cultural knowledge of the destination country and the improvement of cross-cultural competence. Targeted trainings should be provided at least two times per week. They can be set up according to different enterprises and institutions or according to different destination countries. The course has three main purposes: The first is to help students pay more attention to culture and have adequate psychological preparation before going abroad. The second is to popularize the culture of the destination country so that they have more detailed understanding of culture. The third is to cultivate their ability to adapt to these cultures.

Second, enrich teaching content and compile targeted textbooks. We propose that textbooks should be divided into two categories; the first type is knowledge about psychological adjustment and cross-cultural adaptation and the second one is cultural handbook about different countries according to demands of different enterprises, especially the summary of cultural phenomenon. The teaching materials should be explained in a simple way, covering every aspect of daily life, as well as the deep culture behind the reality, and compare Chinese culture and the destination country's culture so that expatriates understand themselves, and the living environment and thinking way abroad better.

Third, make full use of public media and network technology to tap into language and cultural phenomena of the destination country. Students can be exposed to a real language environment through news, films, negotiation videos, and speech on the Internet so as to experience cultural phenomenon in social media.

To sum up, according to the above methods, establishing a three-dimensional curriculum system will provide template and reference for the increasing number of expatriate in language training. While ensuring the improvement of language ability, it is more important to solve practical problems in cross-cultural communication through curriculum reform, so as to ease the anxiety caused by cultural shock and make expatriates adapt to local life and work quickly.

\section{ACKNOWLEDGEMENT}

On the completion of the paper, we would like to express deepest gratitude to all those who received our interview and made this work possible. We would love to give many thanks to Associated Prof. Xue Min whose effective advice, shrewd comments and constructive suggestions have paved the way for our self-development. The authors feel greatly indebted to their families who gave great support for the research of this paper. They constantly encouraged us when we felt frustrated.

\section{REFERENCES}

[1] Redfield, R., Linton, R. and Herskovits, M.T. (1936) Memorandum for the Study of Acculturation. American Anthropologist, 38, 149-152.

[2] Gudykunst W.B. \& Hammer, M.R.(1987). Strangers and hosts: An uncertainty reduction based theory of intellectual adaptation. In Y.Y. Kim \& Gudykunst (Ed.). Cross-cultural adaptation: Current Approaches. Newbury Park, CA: Sage 106-139.

[3] Black,J.S.,\& Gregersen,H.B.(1991).Antecedents to Cross-cultural Adjustment for Expatriates in pacific Rim Assignments. Human Relations, 44.497-515.

[4] Sam,D.L.,\&Berry,J.W.(2006).The Cambridge Handbook of Acculturation Psychology, Cambridge University Press,London:Cambridge:1-11.

[5] Oddou.G.R.(1991). Managing Your Expatriates: What the Successful Firms Do. Journal of Human Resource Planning, 14(4):301-308.

[6] Wilson,M.Chen \& S.\&Erakovic,L.(2006).Dynamics of decision power in the localization process: comparative case studies of China-Western IJVs. International journal of human resource management,17(9):1547-1571.

[7] 王玉梅, 何燕珍, 2014, 跨国外派管理实践对外派人员跨文化适应 的影响--基于中国企业的实证研究, 《经济管理》(5)

[8] 金丹, 2013, 中国企业外派人员的跨文化适应与跨文化培训问题研 究, 广东外语外贸大学 (5) 